\title{
Spanish Inter-Regional Migration: an Enigma Resolved
}

\author{
Alan Mulhern and John Watson \\ School of Economics, \\ Kingston University, Penrhyn Road \\ Kingston upon Thames KT1 2EE
}

UK

\begin{abstract}
This paper demonstrates that Spanish inter-regional migration, for many years unresponsive to traditional explanatory variables, is now explicable in terms of such variables. These include gaps in real wages, unemployment and distance. In the middle of the 1990s there arose an increased responsiveness of regional migration to such explanatory variables.
\end{abstract}

JEL Classification: R23, O15, J61.

Keywords: Regional Migration; Labour Market; Spain; SURE Model

* Corresponding author

Alan Mulhern

School of Economics,

Kingston University, Penrhyn Road

Kingston upon Thames KT1 2EE. UK

e-mail:Alan.Mulhern@kingston.ac.uk 


\section{Introduction}

Spanish inter-regional migration has traditionally been characterized as low by international standards and enigmatically unresponsive to traditional explanatory variables such as real wage and unemployment gaps (Antolin and Bover 1997, Bentolila 1997, Bentolila and Jimeno Serano 1998, Juarez 2000, Lindley et alia 2002, Fonseca 2003). This paper demonstrates firstly, that regional migration in the 1990s became responsive to an explanatory set of economic traditional variables, and secondly, there emerged an increased responsiveness of regional migration to key variables, especially real wages, from the middle of the decade. The motivation of the paper is to show that Spanish regional migration can now be understood within a standard economic framework of regional migration. It is believed that basic economic changes such as labour market reforms underlie the changed immigration dynamics. We also judge whether accelerated international immigration is relevant to this issue.

The Spanish labour market, traditionally characterized by extremely high rates of unemployment, experienced reforms in the 1990s (coinciding with increased inflow of foreign workers). This helps partially explain firstly why real wages fall in the second part of the 1990s despite falling unemployment, and secondly why internal migration increases dramatically in the second period despite falling real wages. We will show in particular that regional migration, as part of the dynamics of the labour market, is responding more sensitively to basic economic stimuli in the second part of the decade.

Section 1 is a literature review. Section 2 specifies the model and obtains results. Section 3 concludes. 


\section{Literature Review.}

Empirical literature on Spanish internal migration traditionally showed that regional real wages and employment differentials were not significantly related to inter-regional migration - despite the indications of Harris-Todaro economic theory (Antolin and Bover 1997, Bentolila 1997 and 2001, Jimeno and Bentolila 1998, Lindley et alia 2002, Maza and Moral-Arce 2006). Researchers frequently found negative results, counter-intuitive signs or very low elasticities on supposed explanatory variables, e.g. regional migration with very low elasticity (or even negative) in response to regional real wages and regional unemployment. However this research had been using data largely prior to 1990. More recently, Maza and Villaverde (2004), have better results but these authors, in line with the trend of previous research, conclude nevertheless that unemployment gaps were not important and that "other determining factors of migration that are non-economic in nature and whose influence is difficult to quantify" must be operating.

Romero-Ávila and Usabiaga (2008) confirm the long standing proposition of hysteresis in the Spanish labour market. Gil Martín (2004) specifies labour market rigidities explaining low elasticity of employment in relation to economic growth, for example, high hiring/firing costs and labour market segmentation (insiders bidding up wages leaving outsiders more precarious and lower paid). The Spanish government initiated many policies to promote employment, such as: reduction of severance pay; intensification of training schemes; different types of contracts to facilitate hiring and firing; better information systems on the labour market addressing the mismatching of demand and supply; decentralisation and privatisation of employment agencies; assistance for the unemployed to set up a small business; technical assistance and management training to 
promote employment in small business; regional fiscal and investment incentives; promotion of local employment initiative; decentralization and speeding up of collective bargaining. Gil Martín reports that as a result the elasticity of employment in respect to economic growth increased although still impeded by labour market segmentation. In addition there was a leap in international immigration especially from 1997 onwards, as GDP increased and unemployment fell, tending to reduce real wages across an increasingly less protected Spanish labour force. Since regional flow figures for these international migrants are not available for much of our time period this variable cannot be incorporated in our model which only measures the flows of those with residency.

Firstly we wish to test the period 1990-2000 to see if inter-regional migration is still resistant to economic theory. We intend therefore to expand the traditional Harris-Todaro specification to include housing prices and infrastructure as explanatory variables. The inclusion of such variables in an extended specification model has been used successfully to explain regional migration in other economies such as Russia and Poland (Andrienko and Guriev 2003, Ghatak et alia 2007). Secondly we expect that that there is a differential response of regional migration to its determining variables in the second compared to the first half of the decade.

\section{Empirical Specification}

We hypothesise that inter-regional migration is explained by regional differences in real wages, unemployment, the price of housing, regional infrastructure facilities and the cost of migration (the proxy of distance is used). We aim to estimate the following equation (2.1): 
$m_{h t y}=c+x_{1} W_{h y}+x_{2} W_{t y}+x_{3} U_{h y}+x_{4} U_{t y}+x_{5} P H_{h y}+x_{6} P H_{t y}+x_{7}$ Infra $a_{h y}+x_{8} I n f r a_{t y}+x_{9} D_{y}+\varepsilon_{h t y}$

Here $m_{h t y}$ is the flow of migrants from region $h$ to region $t$ at year $y$, divided by population in region $h$; where $W$ is real wages, $U$ is the rate of unemployment compared to the active population, $\mathrm{PH}$ is the price of housing, Infra is infrastructure of a region compared to its area; $D$ is distance, a proxy for migration costs; and finally $\varepsilon_{h t y}$ is a random error. Fuller definitions of variables are given in Table 1. Subscripts $h$ and $t$ refer to home and target regions. All variables are transformed to logarithms.

We wish to test the elasticity of migration with respect to its explanatory variables which are denoted as parameters $x$. Given the increase in regional migration in the second half of the decade we also anticipate increased responsiveness of regional migration to these variables and therefore, after testing for a structural break, we divide the data series in two.

We apply a fixed effects model in which we do not estimate the fixed effects directly in order to avoid losing degrees of freedom. We subtract the within mean of each equation in 2.1, and $\mathrm{c}$ is a common constant to all equations. Afterwards we add the within means to obtain the fixed effects of each equation. However, we are not able to show t-statistics on fixed effects. For empirical analysis, we aim to estimate the following equation:

$$
\begin{aligned}
& \log \left(\bar{m}_{h t y}\right)=\log (c)+\sum_{k=1}^{K} x_{k} \log \left(\bar{\beta}_{h t y}\right)+\sum_{s=1}^{S} x_{s} \log \left(\bar{\delta}_{h t y}\right)+\varepsilon_{h t y} \quad \text { if } y<T \\
& \log \left(\bar{m}_{h t y}\right)=\log \left(c^{\prime}{ }_{t}\right)+\sum_{k=1}^{K} x_{k}^{\prime} \log \left({\overline{\beta^{\prime}}}_{h t y}\right)+\sum_{s=1}^{S} x_{s}^{\prime} \log \left({\overline{\delta^{\prime}}}_{h t y}\right)+\varepsilon_{h t y} \quad \text { if } y \geq T
\end{aligned}
$$

$\beta_{h t y}$ are $K$ variables associated to region $h$ at year y; $\delta_{h t y}$ are $S$ variables associated to target region $t$ at year $y ; x$ are elasticities to estimate. In order to investigate a structural break we 
estimate equation 2.1 in two parts, before and after the structural break determined by an $\mathrm{F}$ test.

The random error is assumed to have the following structure:

$$
\begin{gathered}
E\left[\varepsilon_{h t y}\right\rfloor=0, \quad E\left[\varepsilon_{h t y} \varepsilon_{h t y}\right]=\sigma_{t}, \quad E\left[\varepsilon_{h t y} \varepsilon_{h^{\prime} t^{\prime} y}\right]=\sigma_{t} \text { if } t=t^{\prime} \\
\text { and } E\left[\varepsilon_{h t y} \varepsilon_{h^{\prime} t^{\prime} y^{\prime}}\right]=0 \text { otherwise. }
\end{gathered}
$$

Structure (2.3) assumes both groupwise heteroskedasticity and serial correlation of equations when each equation comprises a target region. OLS estimates remain unbiased but inefficient. Tests for groupwise heteroskedasticity and serial correlation were elaborated from OLS estimates of the regressions and none of the hypotheses were rejected. Therefore, the Seemingly Unrelated Regression Equations (SURE) model was applied to the data as SURE estimates bring efficiency gains over OLS estimates (Greene 2000). OLS estimates and statistics for the above-mentioned tests are not presented for brevity purposes but are available from the authors. Moreover the dependent variable may have an influence on independent variables, particularly wages and unemployment. Therefore, we employ lagged variables as instruments. All variables, definitions and sources used are shown in the following table:

Insert Table 1

The first group of variables explain traditional inter-regional migration, i.e. wage and unemployment gaps and distance (proxy of migration costs). House pricing is then included. Public capital in roads, rail and airports (proxy for infrastructure) is used to investigate the effects of regional amenities in migration. The year of structural change, 
1996, was chosen by obtaining F-tests of structural change for each break from 1993 to 1997.

Appendix Table 2 shows results for the whole period 1990-2000. All variables have expected signs except for infrastructure (home region). All are significant except for price of housing (target region). The $\mathrm{R}$ squared at 0.86 is high. We believe this is the first time that Spanish inter-regional migration follows the expectations of economic theory.

Table 3 shows results for 1990-1995. All variables except infrastructure and wages in target regions are significant and all are right signed except infrastructure (home and target regions). Such partial results are expected in the early period before the increased level of labour market reforms. Here there is some resemblance to the partial results of previous research. Again, the R squared is very high.

Table 4 shows the results for second period 1996-2000 and here we expect a significant change. All variables are significant except two, house prices in target region and infrastructure (home region), both with low significance. All variables are right signed and the R squared continues consistently high. The improved results are clear however in the change of elasticities, in the second period compared to the first, of migration with respect to the central variables of wages and unemployment. Our assumption has been that this period will show a greater responsiveness of migration to key variables such as wages and unemployment. Table 4 shows that the coefficient (demonstrating the elasticity) in front of wages in the target region leaps from 0.57 to 7.84 (an increase of 14 times), while wages in home region increase from 1.97 to 3.36 . It should be noted that these large increases in wage elasticity were found in all experiments with the model. With unemployment there is 
also an increased responsiveness of migration in the target region to this variable in the second period.

\section{Conclusion}

Examining the period 1990-2000 this paper has established the existence of a structural break in 1996 indicating an increased response after this date of regional migration to its determining variables, especially that of wages. It is probable that increased labour market reforms have influenced this process opening up the condensed wage structure of the Spanish economy. Increased foreign immigration has probably contributed to less pressure on wage levels in general, but it is the wage gaps that drive internal migration. Our study only examines the migration of those with residency status. Spanish inter-regional migration has therefore now been found in the 1990s to respond to a range of regional economic variables including wages, unemployment and distance. 


\section{References}

Andrienko,Y. and Guriev, S. (2004) Determinants of Inter-Regional Mobility in Russia, Economics of Transition, 12. pp. 1-27.

Antonlin, P. and Bover, O. (1997) Regional Migration in Spain: The Effect of Personal Characteristics and of Unemployment, Wage and of Housing Price Differentials using Pooled Cross-Sections, Oxford Bulletin of Economics and Statistics, 59.2.

Bentolila, S. (1997) Sticky Labor in Spanish Regions, European Economic Review, 41 (35). pp.591-598.

Bentolila, S. and Dolado, J.J. (1990) Mismatch and Internal Migration in Spain, in F.Padoa-Schioppa, (ed), Mismatch and Labor Mobility, Cambridge University Press.

Bentolila, S. (2001) Las migraciones interiores en España, in Documentos de Trabajo 2001-07 FEDEA, May 2001.

Bentolila, S. and Jimeno Serrano,J.F. (1998) Regional Unemployment Persistence (Spain 1976-94), Labour Economics, 5(1). pp. 25-51.

Bover, O. and Arellano, M. (2002) Learning about Migration Decisions from the Migrants: Using Complementary Data Sets to Model Intra-regional Migrations in Spain, Journal of Population Economics, 15 (2). pp. 357-80. 
Devillanova, C. and Garcia Fontes, W. (2004) Migration across Spanish Provinces: Evidence from the Social Security Records. 1978-1992, Investigaciones Económicas, 28.3. pp.461-487.

Fonseca, R. (2003) On the Interaction between Unemployment and Inter-regional Mobility, CSEF Working Papers 105, Centre for Studies in Economics and Finance (CSEF), University of Salerno, Italy.

Ghatak, S., Mulhern, A. and Watson, J. (2008) Inter-Regional Migration in Transition Economies: The Case of Poland, Review of Development Economics, 12(1). pp.209-222.

Gil Martín, S. (2004) An Overview of Spanish Labour Markets Reforms, 1985-2002. Unidad de Políticas Comparadas. Working Paper 17-02. European University Institute.

Greene, William H. (2000) Econometric Analysis. Prentice Hall.

Harris, J. and Todaro, M. (1970) Migration, Unemployment and Development: A TwoSector Analysis, American Economic Review, 60. pp.126-142.

Juarez, J.P. (2000) Analysis of Interregional Labor Migration in Spain Using Gross Flows, Journal of Regional Science, 40.(2). pp. 377-399.

Instituto Nacional de Estadística: Madrid. http://www.ine.es 
Lindley, J., Upward, R.., Wright, P. (2002) Regional mobility and unemployment transitions in the UK and Spain, in Leverhulme Centre for Research on Globalisation and Economic Policy. University of Nottingham. Oct $4^{\text {th }}$. Also GEP Working Paper No. 02/19. Available at SSRN (Social Science Research Network).

Maza, A. and Moral-Arce, I. (2006) An Analysis of Wage Flexibility: Evidence from the Spanish Regions, Annals of Regional Science, 40(3). 2006. pp. 621-637.

Maza, A. and Villaverde, J. (2004) Interregional migration in Spain: a semiparametric analysis, The Review of Regional Studies. 34(2). pp.37-52.

Romero-Ávila, D. and Usabiaga, C. (2008) On the persistence of Spanish unemployment rates, Journal Empirical Economics. 35(1). pp.77-99. 


\section{Table 1}

Variable Definition and Sources

M

Migration from home to target region as a proportion of population of home region. Official statistics of those with residency qualifications.

Source: INE = Instituto Nacional de Estatistica.

$\mathrm{Wt}$ and $\mathrm{Wh}$

Average wage per month deflated by Consumer Price Index (not including housing prices) in target (t) and home $(\mathrm{h})$ region.

Source: Encuesta de Salarios en la Industria y Servicios INE.

Source: Índice de precios de consumo. Base 1992. INE.

Ut and Uh

Percentage of unemployed over active population in target (t) and home (h) region. Source: Encuesta de Población Activa. INE.

$\mathrm{PHt}$ and PHh Average housing prices by mtrs2 deflated by $\mathrm{CPI}$, target $(\mathrm{t})$ and home $(\mathrm{h})$ region. Source: Índice de precios de consumo. Base 1992. INE.

Source: Instituto de Investigaciones de Andalucía.

D

Distance in $\mathrm{KM}$ of road distance between capitals. Canarias and Balears show aerial distanc

INFRAt INFRAh Capital Stock in urban infrastructure, roads, trains and airports divided by area. Source: BDMORES regional database. 


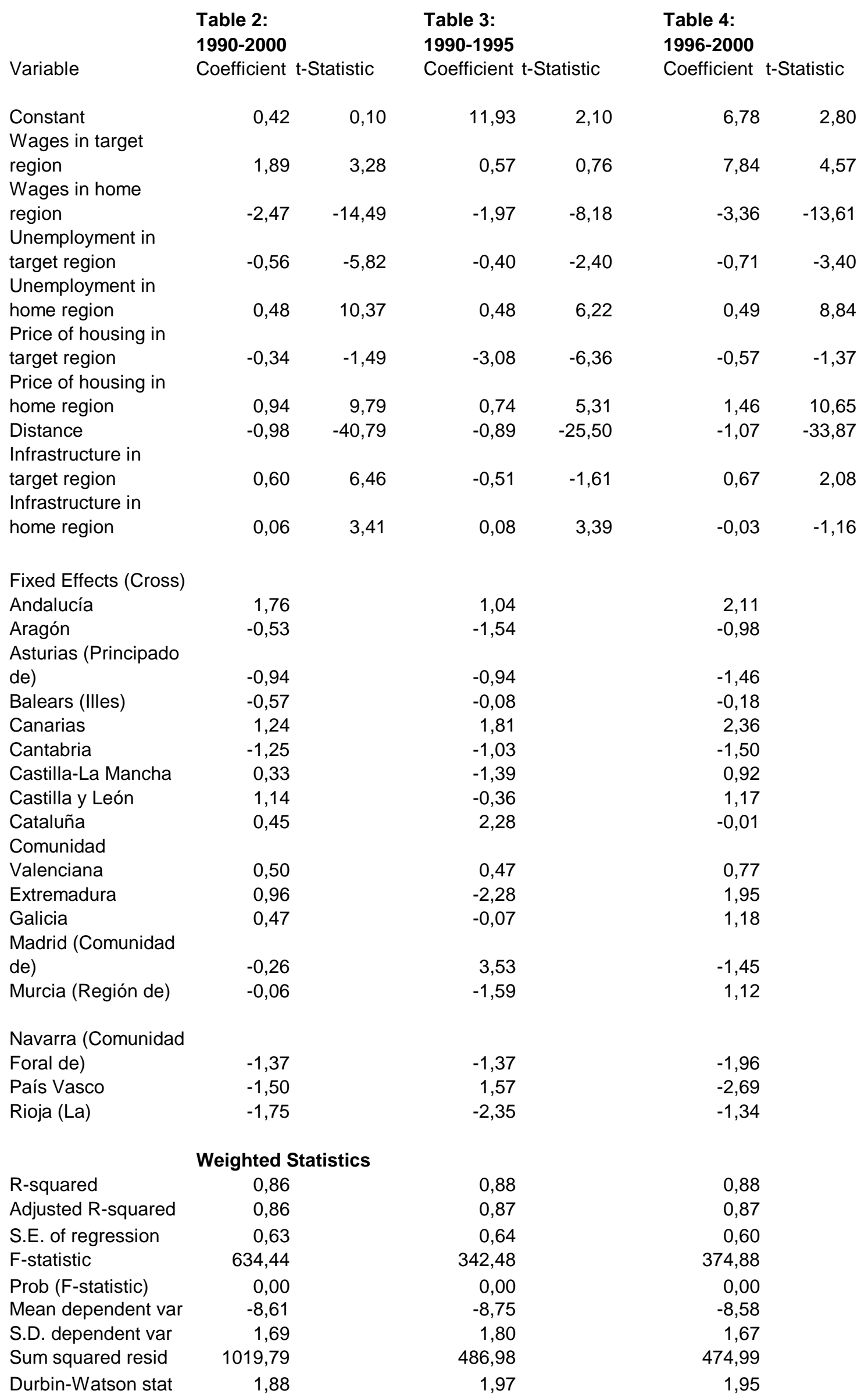

